\title{
Distribution and Determinants of Etiologies and Complications of Chronic Liver Diseases Among Patients at a Tertiary Hospital in a Lower Economic Region of Ghana
}

\author{
Matthew Aidoo, $^{1,}$, Baba Sulemana Mohammed ${ }^{2}$ \\ ${ }^{1}$ Directorate of Pharmacy, Tamale Teaching Hospital, Tamale, Ghana \\ ${ }^{2}$ Department of Pharmacy, University for Development Studies, Tamale, Ghana \\ Email address: \\ pharmkobbymatt@yahoo.com (M. Aidoo), mbsule@uds.edu.gh (B. S Mohammed) \\ ${ }^{*}$ Corresponding author
}

\section{To cite this article:}

Matthew Aidoo, Baba Sulemana Mohammed. Distribution and Determinants of Etiologies and Complications of Chronic Liver Diseases Among Patients at a Tertiary Hospital in a Lower Economic Region of Ghana. Central African Journal of Public Health. Vol. 6, No. 5, 2020, pp. 280-287. doi: 10.11648/j.cajph.20200605.16

Received: September 4, 2020; Accepted: September 17, 2020; Published: September 25, 2020

\begin{abstract}
There is dearth of data on the epidemiology of chronic liver diseases (CLDs) in northern Ghana. To this extent, we intended to investigate the distribution and determinants of the etiologies and complications of CLDs at the Tamale Teaching Hospital, a referral hospital of northern Ghana. The medical records of patients with CLDs admitted at the medical ward of Tamale Teaching Hospital from June to December 2019 were reviewed in a retrospective cross-sectional study. Out of 180 patients reviewed, $130(72.2 \%)$ were males; the age range was 18-86 years, with a mean age of 4143 years. Etiologies of CLDs comprised hepatis B viral infection (53.3\%), hepatitis C viral infection (21.7\%), unknown (9.4\%), hepatocellular carcinoma (8.9\%), and alcoholic liver disease (6.7\%). Among the complications of CLDs; cirrhosis (71.1\%), hypoalbuminemia $(59.4 \%)$, ascites $(58.3 \%)$ and jaundice $(52.2 \%)$ occurred in more than half of the patients. Age $(\mathrm{p}=<0.001)$, education $(\mathrm{p}=0.005)$ and intake of herbal medicine $(\mathrm{p}=0.001)$ were associated with the etiologies of CLDs. There was a significant association between the etiologies of CLDs and complications; cirrhosis $(p=<0.001)$, hypoalbuminemia $(p=0.003)$, ascites $(p=<0.001)$, and jaundice $(\mathrm{p}=0.009)$. Hepatitis $\mathrm{B}$ and hepatitis $\mathrm{C}$ viral infections were the main etiologies of CLDs. Young/middle age, noneducation and intake of herbal medicine were risk factors for the main etiologies of CLDs. Cirrhosis, hypoalbuminemia, ascites, and jaundice were the major complications of CLDs. Chronic hepatitis B and C viral infections were risk factors for developing the major complications of CLDs. Implementation of integrated public health strategies targeted at risk groups (young/middle age adults, illiterates, consumers of herbal medicine, patients with hepatitis B and C viral infections) may help curtail the burden of CLDs in northern Ghana.
\end{abstract}

Keywords: Chronic, Complications, Determinants, Diseases, Distribution, Etiologies, Liver

\section{Introduction}

Chronic liver diseases (CLDs) are persistent inflammatory conditions of the liver in which the biochemical and histopathological abnormalities of the liver are present over a long period [1]. It consists of a wide range of liver pathologies of different etiologies existing on a continuum between chronic hepatitis, cirrhosis and hepatocellular carcinoma.

CLDs exemplify a critical global public health problem, because it causes substantial morbidity and mortality worldwide. It has been estimated that about 844 million people globally have CLDs, with 2 million deaths per year, which is comparable to the morbidity and mortality of other major public health diseases like diabetes mellitus (422 million cases, and 1.6 million deaths), respiratory diseases (650 million cases, and 6.17 million deaths) and cardiovascular diseases (540 million cases, 17.7 million deaths) [2]. 
Globally, the distribution of CLDs comprises non-alcoholic fatty liver diseases [NALD] $(60 \%)$, hepatitis B viral infection [HBV] (29\%), hepatitis C viral infection [HCV] (9\%), and alcoholic liver diseases [ALD] (2\%) [3]. However, depending on the geographical prevalence of etiologies (hepatitis viruses, alcohol consumption, and metabolic syndrome), a large degree of geographical variation exist in the pattern of CLDs [4]. For instance, viral hepatitis is prevalent in Africa, Asia and Latin America, whereas ALD and NALD is predominant in Western countries [2]. The morbidity and mortality of CLDs are mainly due to its complications (ascites, hepatic encephalopathy, hepatorenal syndrome, variceal hemorrhage and hepatocellular carcinoma). Yet again, the distribution of complications of CLDs will differ due to the common etiologies of CLDs in a setting. For example, chronic HBV infection accounts for more than $70 \%$ of hepatocellular carcinoma cases in Africa and Asia, but about 50\% of cases globally [5]. It is therefore important to identify the geographical epidemiology of CLDs to help implement specific strategies to curtail the burden of CLDs in that setting.

From search of the literature there was dearth of data on the epidemiology of CLDs in northern Ghana. This research, was thus aimed to study the distribution and determinants of the etiologies and complications of CLDs among patients presenting at a tertiary hospital in northern Ghana.

\section{Methods}

\subsection{Study Design and Site}

A retrospective cross-sectional study was carried out on patients with CLDs at the medical ward of the Tamale Teaching Hospital. The Tamale Teaching Hospital is a tertiary and referral hospital for the northern sector of Ghana, as well as an institution for training of health professionals.

\subsection{Patients and Inclusion Criteria}

Patients on admission at the medical ward of Tamale Teaching Hospital from June-December 2019 were included in the study. Only patients diagnosed of CLD and $\geq 18$ years of age were eligible for the research. Diagnosis of CLD was made among patients with evidence of liver disease (elevated liver enzymes, high bilirubin, and/or low albumin levels) by liver function test (S1 Table) The diagnosis was done according to the following criteria: (i) abdominal imaging (ultrasound) showing hepatic parenchyma heterogeneity and/or surface irregularity suggestive of chronic hepatitis, cirrhosis, or hepatocellular carcinoma [6] or (ii) presence of clinical features of decompensated liver diseases such as ascites, bleeding, jaundice, and hepatic encephalopathy [7].

\subsection{Data Collection}

Data from the medical records of all eligible patients were collected into an excel spread sheet. Data collected included socio-demographic characteristics (sex, age, and educational background); history of alternative medical treatment (intake of herbal medicine); and clinical characteristics (etiologies and complications of CLDs). Etiologies and complications of
CLD were defined according to the criteria in (S2 Table) and (S3 Table) respectively.

\subsection{Data Analysis}

Descriptive information on the patients' demographic and clinical characteristics were performed and illustrated in proportions with the aid of tables and figures. Analysis of the determinants of the etiologies and complications of CLDs was performed using Statistical Package for the Social Sciences (SPSS) Version 25. Fisher exact test was used to investigate for a significant association between (demographics and etiologies of CLD) and (etiologies and complications of CLD) at $\mathrm{p}$-value of less than 0.05 . Multinomial logistic regression with $95 \%$ confidence interval was utilized to determine the predictive effects of associated variables.

\subsection{Ethical Consideration}

Permission was sought from the management of the Tamale Teaching Hospital to conduct the study through an application containing a summary of the study proposal to the research and ethics committee of TTH. Authorization was granted before the study commenced.

\section{Results}

\subsection{Demographic Characteristics of Patients}

A total of 180 patients with CLDs were included in the study. Gender composition of the patients indicated that males were majority; $72.2 \%$ (Table 1 ). The age range of the patients was 18 to 86 years, with a mean age of 43 years. A greater proportion of the patients were in the age group of $18-39$ years $(43.9 \%)$ and $40-59$ years $(40.6 \%)$. More than half of the patients had no formal education $136(75.6 \%)$. Drug history of intake of herbal medicine showed that majority of the patients $(59.4 \%)$ had consume herbal medicine (Table 1).

Table 1. Demographic characteristics of the patients.

\begin{tabular}{lll}
\hline Characteristic & Frequency & Percentage \\
\hline Gender & & \\
Male & 130 & 72.2 \\
Female & 50 & 27.8 \\
Age range & & \\
$18-39$ & 79 & 43.9 \\
$40-59$ & 73 & 40.6 \\
$\geq 60$ & 28 & 15.6 \\
Education & & \\
Educated & 44 & 24.4 \\
Non-educated & 136 & 75.6 \\
Intake of herbal & & \\
Yes & 107 & 59.4 \\
No & 73 & 40.6 \\
\hline
\end{tabular}

\subsection{Distribution of Etiologies of Chronic Liver Diseases}

The etiologies among the patients showed that hepatitis B viral infection was the major cause of CLDs 96 (53.3\%), followed by hepatitis $\mathrm{C}$ viral infection 39 (21.7\%), unknown 
17 (9.4\%), hepatocecular carcinoma 16 (8.9\%), and alcoholic liver disease 12 (6.7\%) (Figure 1).

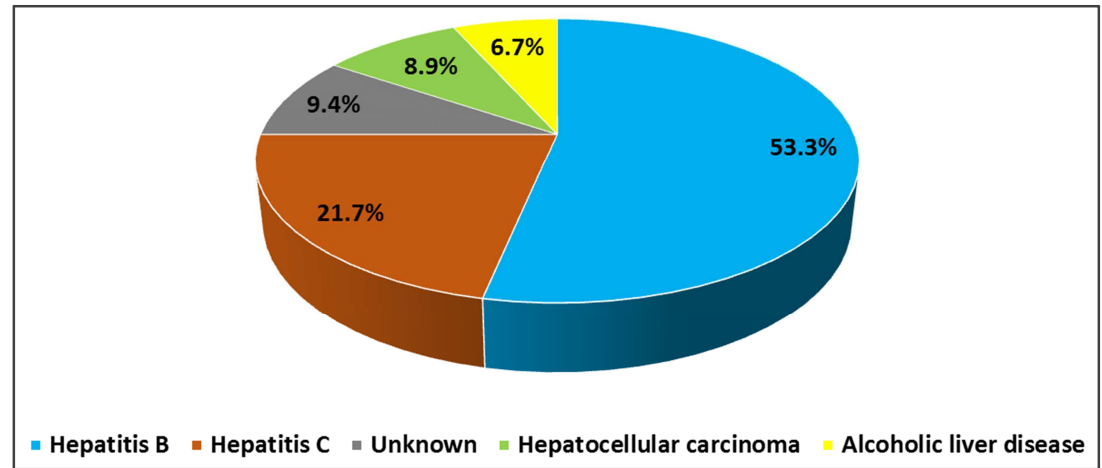

Figure 1. Distribution of etiologies of chronic liver diseases.

\subsection{Distribution of Complications of Chronic Liver Diseases}

The following were major complications among the CLD patients; cirrhosis 129 (71.7\%), hypoalbuminemia 107 (59.4\%), ascites 105 (58.3\%) and jaundice 94 (52.2\%)
(Figure 2). These complications: infections, upper gastrointestinal bleeding, hyponatremia, hepatorenal syndrome, hepatic encephalopathy, and varices occurred in less than $50 \%$ of the patients.

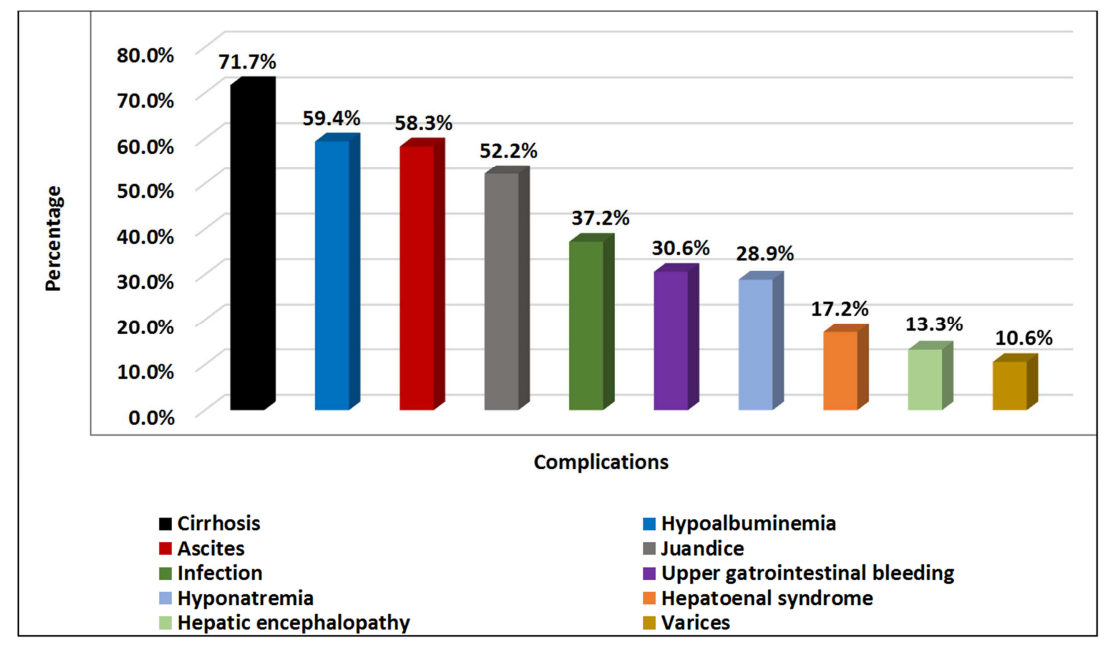

Figure 2. Distribution of complications of chronic liver disease

\subsection{Determinants of Etiologies of Chronic Liver Diseases}

Analysis of etiologies among the CLD patients revealed that age, education background, and history of intake of herbal medicine were significantly associated with the etiologies of CLD; $(p=<0.001), \quad(0.005)$ and $(0.001)$ respectively (Table 2).

Table 2. Association between demographic characteristics and etiologies of CLD.

\begin{tabular}{|c|c|c|c|c|c|c|}
\hline \multirow{2}{*}{$\begin{array}{l}\text { Demographic } \\
\text { characteristics }\end{array}$} & \multicolumn{6}{|c|}{ Etiologies of CLD } \\
\hline & $\operatorname{ALD}(n=12)$ & HBV $(n=96)$ & HCV $(n=39)$ & HCC $(n=16)$ & Unknown $(n=17)$ & Fisher exact $P$-value \\
\hline Gender & & & & & & 0.199 \\
\hline Male & $9(75.0)$ & $75(78.1)$ & $23(59.0)$ & $10(62.5)$ & $13(76.5)$ & \\
\hline Female & $3(25.0)$ & $21(21.9)$ & $16(41.0)$ & $6(37.5)$ & $4(23.5)$ & \\
\hline Age (years) & & & & & & $<0.001$ \\
\hline $18-39$ & $3(25.0)$ & $60(62.5)$ & $4(10.3)$ & $5(31.3)$ & $7(41.2)$ & \\
\hline $40-59$ & $7(58.3)$ & $31(32.3)$ & $21(53.8)$ & $9(56.3)$ & $5(29.4)$ & \\
\hline Education & & & & & & 0.005 \\
\hline Non-educated & $7(58.3)$ & $76(79.2)$ & $35(89.7)$ & $9(56.3)$ & $9(52.9)$ & \\
\hline Educated & $5(41.7)$ & $20(20.8)$ & $4(10.3)$ & $7(43.8)$ & $8(47.1)$ & \\
\hline Intake of herbal & & & & & & 0.001 \\
\hline Yes & $5(41.7)$ & $66(68.8)$ & $26(66.7)$ & $4(25.0)$ & $6(35.3)$ & \\
\hline No & $7(58.3)$ & $30(41.1)$ & $13(33.3)$ & $12(75.0)$ & $11(64.7)$ & \\
\hline
\end{tabular}


Patients between age 18-39 years and 40-59 years were 8.6 times and 6.2 times more likely to have chronic HBV infection. Non-educated patients were more at risk of developing chronic HBV $(\mathrm{AOR}=3.4,95 \% \mathrm{CI}: 1.2-9.8, \mathrm{p}=0.026)$, and chronic
$\mathrm{HCV}$ infections (AOR=7.8, 95\% CI: 1.9-31.7, $\mathrm{p}=0.004)$. There was 4 times and 3.7 times higher likelihood to develop CLD from HBV and HCV infections among patients with history of intake of herbal medicine (Table 3 ).

Table 3. Multinomial logistic regression analysis of demographic characteristics and etiologies CLD.

\begin{tabular}{|c|c|c|c|c|c|c|c|c|}
\hline \multirow{4}{*}{$\begin{array}{l}\text { Etiologies } \\
\text { of CLD }\end{array}$} & \multicolumn{8}{|c|}{ Demographic characteristics } \\
\hline & \multicolumn{4}{|c|}{ Age (years) ${ }^{1}$} & \multicolumn{2}{|c|}{ Education $^{2}$} & \multicolumn{2}{|c|}{ Intake of herbal $^{3}$} \\
\hline & \multicolumn{2}{|c|}{$18-39$} & \multicolumn{2}{|l|}{$40-59$} & \multicolumn{2}{|c|}{ Non-educated } & \multicolumn{2}{|c|}{ Yes } \\
\hline & P-value & AOR (CI: 95\%) & P-value & AOR (CI: 95\%) & P-value & AOR (CI: 95\%) & P-value & AOR (CI: 95\%) \\
\hline ALD & 0.949 & $1.1(0.1-8.9)$ & 0.220 & $3.5(0.4-25.9)$ & 0.774 & $1.2(0.3-5.5)$ & 0.728 & $1.3(0.3-6.0)$ \\
\hline $\mathrm{HBV}$ & 0.004 & $8.6(2.0-37.1)$ & 0.022 & $6.2(1.3-29.5)$ & 0.026 & $3.4(1.2-9.8)$ & 0.012 & $4.0(1.4-11.9)$ \\
\hline $\mathrm{HCV}$ & 0.051 & $0.2(0.1-1.0)$ & 0.574 & $1.5(0.4-6.2)$ & 0.004 & $7.8(1.9-31.7)$ & 0.033 & $3.7(1.1-12.1)$ \\
\hline $\mathrm{HCC}$ & 0.570 & $1.8(0.2-13.2)$ & 0.135 & $4.5(0.6-32.3)$ & 0.849 & $1.1(0.3-4.5)$ & 0.522 & $0.6(0.1-2.8)$ \\
\hline
\end{tabular}

${ }^{1}$ Age $\geq 60$ is the reference category.

${ }^{2}$ Educated is the reference category.

${ }^{3}$ No intake of herbal medicine is the reference category.

\subsection{Determinants of Complications of Chronic Liver Diseases}

The risk of developing cirrhosis $(p=<0.001)$, hypoalbuminemia $(p=0.003)$, ascites $(p=<0.001)$ and jaundice $(p=0.009)$ were significantly associated with the etiologies of CLD (Table 4).

Table 4. Association between etiologies and complications of CLD.

\begin{tabular}{|c|c|c|c|c|c|c|}
\hline \multirow{3}{*}{ Complications of CLD } & \multicolumn{6}{|c|}{ Etiologies of CLD } \\
\hline & ALD & HBV & HCV & $\mathrm{HCC}$ & Unknown & Fisher exact \\
\hline & $(n=12)$ & $(n=96)$ & $(n=39)$ & $(n=16)$ & $(n=17)$ & P-value \\
\hline Cirrhosis & $4(33.3)$ & $81(84.4)$ & $32(81.1)$ & $4(25.0)$ & $8(47.1)$ & $<0.001$ \\
\hline Hypoalbuminemia & $4(33.3)$ & $62(64.6)$ & $29(74.4)$ & $6(37.5)$ & $6(35.3)$ & 0.003 \\
\hline Ascites & $3(25.0)$ & $68(70.8)$ & $26(66.7)$ & $2(12.5)$ & $6(35.3)$ & $<0.001$ \\
\hline Jaundice & $7(58.3)$ & $60(62.5)$ & $18(46.2)$ & $4(25.0)$ & $5(29.4)$ & 0.009 \\
\hline UGIB & $4(33.3)$ & $33(34.4)$ & $13(33.3)$ & $2(12.5)$ & $3(17.6)$ & 0.333 \\
\hline Hyponatremia & $6(50.0)$ & $27(28.1)$ & $13(33.3)$ & $3(18.8)$ & $3(17.6)$ & 0.306 \\
\hline HRS & $1(8.3)$ & $15(15.6)$ & $10(25.6)$ & $1(6.3)$ & $4(23.5)$ & 0.333 \\
\hline HE & $2(16.7)$ & $15(15.6)$ & $4(10.3)$ & $1(6.3)$ & $2(11.8)$ & 0.826 \\
\hline Varices & $2(16.7)$ & $11(11.5)$ & $4(10.3)$ & $1(6.3)$ & $1(5.9)$ & 0.880 \\
\hline
\end{tabular}

Multinomial regression indicated that patients who had HBV (AOR=6.1, 95\% CI: 2.0-18.3, $\mathrm{p}=0.001)$ and $\mathrm{HCV}$ infections $(\mathrm{AOR}=5.1,95 \% \mathrm{CI}: 1.5-18.0, \mathrm{p}=0.011)$ were more at risk to develop cirrhosis (Table 5). The risk of developing hypoalbuminemia was 3.3 and 5.3 times more likely among CLD patients with $\mathrm{HBV}$ and $\mathrm{HCV}$ etiologies respectively.
Additionally, patients with viral hepatis $\mathrm{B}$ and $\mathrm{C}$ as the cause of their CLD had 45\% and 37\% respectively, higher likelihood to develop ascites. A complication of jaundice was more likely to occur in patients who were infected with chronic HBV (AOR=4.0, 95\% CI: 1.3-12.3, $\mathrm{p}=0.015)$ (Table 5).

Table 5. Multinomial logistic regression analysis of etiologies and complications of CLD.

\begin{tabular}{|c|c|c|c|c|c|c|c|c|}
\hline \multirow{3}{*}{$\begin{array}{l}\text { Etiologies } \\
\text { of CLD }\end{array}$} & \multicolumn{8}{|c|}{ Complications of CLD } \\
\hline & \multicolumn{2}{|c|}{ Cirrhosis $^{1}$} & \multicolumn{2}{|c|}{ Hypoalbuminemia $^{2}$} & \multicolumn{2}{|l|}{ Ascites $^{3}$} & \multicolumn{2}{|c|}{ Jaundice $^{4}$} \\
\hline & P-value & AOR (CI: 95\%) & P-value & AOR (CI: 95\%) & P-value & AOR (CI: 95\%) & P-value & AOR (CI: 95\%) \\
\hline ALD & 0.462 & $0.6(0.1-2.6)$ & 0.913 & $0.9(0.2-4.4)$ & 0.557 & $0.6(0.1-3.2)$ & 0.126 & $3.4(0.7-15.8)$ \\
\hline HBV & 0.001 & $6.1(2.0-18.3)$ & 0.028 & $3.3(1.1-9.8)$ & 0.007 & $4.5(1.5-13.2)$ & 0.015 & $4.0(1.3-12.3)$ \\
\hline $\mathrm{HCV}$ & 0.011 & $5.1(1.5-18.0)$ & 0.008 & $5.3(1.6-18.1)$ & 0.033 & $3.7(1.1-12.1)$ & 0.246 & $2.1(0.6-7.0)$ \\
\hline $\mathrm{HCC}$ & 0.194 & $0.4(0.1-1.6)$ & 0.895 & $1.1(0.3-4.5)$ & 0.141 & $0.3(0.1-1.6)$ & 0.776 & $0.8(0.2-3.7)$ \\
\hline
\end{tabular}

${ }^{1}$ Presence of cirrhosis.

${ }^{2}$ Presence of hypoalbuminemia.

${ }^{3}$ Presence of ascites.

${ }^{4}$ Presence of jaundice. 


\section{Discussion}

\subsection{Demographic Characteristics of Patients}

The study found out a male gender preponderance among the CLD patients and this was comparable to observations from studies elsewhere in Africa [8] Asia [9] Europe [10] and America [11]. This may imply that male gender is a high-risk group for CLDs. The mean age of the CLD patients (43 years) was similar to the findings in another study in Nigeria (44 years) [12]; and Nepal (42 years) [13]. Additionally, CLD was higher among patients with younger age (18-39 years) and middle age (40-59 years) [14]. The young and/or middle age are mostly at high risk of environmental (heavy alcohol use, smoking) and human exposure (unprotected sex, blood and body fluids) which may point to the high incidence of CLD in this age group. It was also noted that majority of the patients did not have formal education (illiterates). The Northern region is the region with the highest adult illiteracy rate in Ghana [15], which may explain the higher noneducated adult study participants. Drug history of the study population showed that majority $(59.4 \%)$ were exposed to herbal medicine consumption, which was comparatively higher than the $(45.5 \%)$ in Enugu state [8], but lower compared with the $(68.5 \%)$ in Calabar [16]. It is estimated that more than $75 \%$ of the populace in sub-Saharan Africa depend on traditional herbal medicine for primary health care [17]. Thus, the observation in this study reflects the use of herbal medicine in a sub-Saharan African setting for health care including liver diseases.

\subsection{Distribution and Determinants of Etiologies of Chronic Liver Diseases}

A review of the etiologies indicated that $\mathrm{HBV}$ was the major etiology of CLD (53.3\%). Other studies in African countries have identified a comparable major pattern of HBV infection among CLD patients: (57.7\%) in Ethiopia [18] and (58.0\%) in Nigeria [12]. A greater proportion of the patients (21.7\%) had $\mathrm{HCV}$ as the cause of their CLD which was similar to the $(22.5 \%)$ obtained in Ethiopia [19], however very low compared to the $(43.1 \%)$ in Italy [4]. The geographical variations may have contributed to this findings, which implies that the prevalence of $\mathrm{HCV}$ infection among individuals with CLD is higher in Europe compared to Africa.

There was high risk of HBV infection among young and middle age adults. Other studies in Ghana have identified high prevalence of HBV among young and middle age adults $[20,21]$. Young and/or middle age adults are more likely to engage in high-risk sexual activities; one of the most frequent routes of transmission for HBV among adults [22]. Again, young/middle age adults are likely to have more social contacts, and frequently visit settings (e.g. barber, and beauty care centers) which have been associated with transmission of HBV infection [23].

Patients with no formal education (illiterates) were associated with higher likelihood of being infected with HBV and HCV. It has been noted that both $\mathrm{HBV}$ and $\mathrm{HCV}$ infections are rapidly increasing in developing countries due to lack of health education, poverty and illiteracy [24]. Illiteracy has direct impact on human health, as it prevents people from access to the vast global store of written information [25]. This implies that written information on modes of transmission and preventive measures of infectious diseases including HBV and HCV infections are likely to be oblivious to individuals without formal education. Limited health literacy has been associated with reduced adoption of protective behaviours such as immunization, less participation in health-promotion and disease-detection activities. [26, 27].

Patients with history of intake of herbal medicines were more likely to develop CLD from HBV and HCV infections. Herbal medicines have been associated with liver fibrosis and increased risk of developing CLDs [28, 29]. Therefore, liver injury due to consumption of herbal medicines either prior or post $\mathrm{HBV}$ and HCV infection are highly likely to progress to chronic HBV and HCV infections. Patients may use herbal medicines because they believe these are products of natural origin and thus safe for consumption. However the literature has proven this ideology to be untrue with reports of hepatotoxicity from the use of herbal medicines [17]. Hepatoxicity from herbal medicines can result from; use of herbs with unknown toxicity; incorrect identification of herbs leading to substitution of non-poisonous herb with a toxic herb; potentiation of the toxic effect of a conventional drug; and the presence of chemicals and heavy metals [30, 31].

\subsection{Distribution and Determinants of Complications of Chronic Liver Diseases}

It was found out that cirrhosis, hypoalbuminemia, ascites, and jaundice were the major complications among the CLD patients. This indicates that majority of the patients were in decompensated cirrhotic phase of CLD at the time they were presenting to the hospital. The prognosis among these patients are likely to be poor because the estimated one-year mortality among decompensated patients is high; $20-57 \%$ [32]. This obviously indicates the need for early testing and treatment among high risk populations as this is necessary to reduce the burden of liver diseases.

It was observed that there was a high risk of developing liver cirrhosis among CLD patients who were infected with $\mathrm{HBV}$ and $\mathrm{HCV}$. Infection with $\mathrm{HBV}$ and $\mathrm{HCV}$ particularly lead to CLD and, together have been the major causes of liver cirrhosis worldwide $[33,34]$. It is known that about 8 $20 \%$ of patients who get infected with HBV will progress to chronicity and develop cirrhosis within 5 years of infection [35], whereas $15-30 \%$ of persons who contract $\mathrm{HCV}$ will get chronic and then advance to cirrhosis within 20 years [36]. The progression of chronic $\mathrm{HBV}$ or $\mathrm{HCV}$ to cirrhosis depends on a number of factors (host and virus). In the case of HBV infection, these factors include; alcohol consumption, smoking, male gender, co-infection with hepatitis $\mathrm{C}$ or $\mathrm{D}$ virus and $\mathrm{HBV}$ genotype $(\mathrm{C}>\mathrm{B}$; D $>\mathrm{A})$ [37]. Others are 
elevated serum levels of total bilirubin, AST/ALT ratio, HBV DNA, and positivity of $\mathrm{HBeAg}[38,37]$. Important factors for the progression of chronic $\mathrm{HCV}$ infection to cirrhosis include non-modifiable (male sex, age at which infection was acquired, and race), modifiable (alcohol abuse, smoking, insulin resistance, and co-infection with hepatitis B, HIV or schistosomiasis) [39] and HCV genotypes (HCV $2<\mathrm{HCV} 4$ $<\mathrm{HCV} 1<\mathrm{HCV} 3$ ) [40].

In this study, the risk of developing hypoalbuminemia was more likely to occur among patients with chronic viral hepatitis. Since majority of the patients with chronic HBV and HCV infections in this study had clinical decompensated complications (advanced cirrhosis) it could explain the association between hypoalbuminemia and viral infections. Patients with advanced cirrhosis almost always have hypoalbuminemia caused by both decreased synthetic function of the liver cells and water and sodium retention that dilutes the content of the albumin in the extracellular compartment [41]. A significant association have been found between the severity of hepatic cirrhosis and decreased albumin levels in patients with chronic HBV [42]. Similarly, the risk of hypoalbuminemia increased significantly in chronic HCV patients with advanced fibrosis [43].

We found out that, $\mathrm{HBV}$ and $\mathrm{HCV}$ infections were significant risk factors for a patient to develop ascites. Liver cirrhosis is the most common cause of ascites [44]. In patients with liver cirrhosis ascites develops mainly due to portal hypertension [45]. Additionally, hypoalbuminemia favors the extravasation of fluid from plasma to the peritoneal cavity and therefore, ascites is rare in patients with liver cirrhosis unless there is existence of both portal hypertension and hypoalbuminemia [46]. Since patients with chronic HBV and HCV infections were more likely to have cirrhosis, and hypoalbuminemia, it may offer a basis for the relationship between $\mathrm{HBV}$ and $\mathrm{HCV}$ infections and the development ascites.

Patients with HBV infection had significant risk of developing jaundice as a complication, a finding that has been demonstrated by other studies in Ghana [47] and Kenya [48]. Jaundice is an indication of hepatic decompensation and occurs as a result of impaired conjugation of bilirubin and biliary excretion of conjugated bilirubin.

\section{Conclusion}

$\mathrm{HBV}$ and HCV infections were the main etiologies of CLDs. Young/middle adult age, non-education and intake of herbal medicine were risk factors associated with chronic $\mathrm{HBV}$ and $\mathrm{HCV}$ infections. Cirrhosis, hypoalbuminemia, ascites, and jaundice were the major complications of CLDs. $\mathrm{HBV}$ and $\mathrm{HCV}$ infections were risk factors for developing the major complications of CLDs. Implementation of integrated public health strategies such as education, screening, vaccination among high risk groups (young/middle age adult, illiterates, herbal medicine consumers), and early treatment of patients with HBV and $\mathrm{HCV}$ infections may help curtail the burden of CLDs in northern Ghana as well the entire country.

\section{Acknowledgements}

The authors want to express their profound gratitude to the management of the Tamale Teaching Hospital for their permission for this study. We would also thank the staff of the Medical Ward of the hospital for their assistance to access the medical records of the patients.

\section{References}

[1] OMICS, "Chronic Liver Diseases," 2020. [Online]. Available: https://www.omicsonline.org. [Accessed: 18-Jul-2020].

[2] P. Marcellin and B. K. Kutala, "Liver diseases: A major, neglected global public health problem requiring urgent actions and large-scale screening," Liver Int., vol. 38, no, suppl. 1, pp. 2-6, 2018.

[3] A. M. Mooon, A. G. Signal, and E. B. Tapper, "Contemporary Epidemiology of Chronic Liver Disease and Cirrhosis," Clin Gastroenterol Hepatol, vol. S1542-3565, no. 19, pp. 30849-3, 2019.

[4] U. Fedeli, F. Avossa, E. Ferroni, A. De Paoli, F. Donato, and M. Chiara, "Prevalence of chronic liver disease among young / middle-aged adults in Northern Italy : role of hepatitis B and hepatitis $\mathrm{C}$ virus infection by age, sex, ethnicity," Heliyon, vol. 5, no. 7, p. e02114, 2019.

[5] X. Wang et al., "Study of liver cirrhosis over ten consecutive years in Southern China," World J Gastroenterol, vol. 20, no. 37, pp. 13546-13555, 2014.

[6] R. Allan, K. Thoirs, and M. Phillips, "Accuracy of ultrasound to identify chronic liver disease," World J. Gastroenterol., vol. 16, no. 28, pp. 3510-3520, 2010.

[7] EASL, "Clinical Practice Guidelines OF HEPATOLOGY EASL Clinical Practice Guidelines for the management of patients with decompensated cirrhosis q Clinical Practice Guidelines," J. Hepatol., vol. xxx, pp. 1-55, 2018.

[8] S. C. Nwokediuko, P. C. Osuala, U. V Uduma, A. K. Alaneme, C. C. Onwuka, and C. Mesigo, "Pattern of liver disease admissions in a Nigerian tertiary hospital," Niger J Clin Pr. vol. 16 , no. 3, pp. 339-342, 2013.

[9] G. Choudhuri, S. Chaudhari, D. Pawar, and D. Sen Roy, "Etiological Patterns, Liver Fibrosis Stages and Prescribing Patterns of Hepato-Protective Agents in Indian Patients with Chronic Liver Disease," J Assoc Physicians India, vol. 66, no. 12, pp. 58-63, 2018.

[10] E. Sagnelli, C. Sagnelli, and M. Pirisi, "Gender differences in chronic liver diseases in two cohorts of 2001 and 2014 in Italy," Infection, vol. 46, no. 1, pp. 93-101, 2018.

[11] G. Hirode, S. Saab, and R. J. Wong, "Trends in the Burden of Chronic Liver Disease Among Hospitalized US Adults," Gastroenterol. Hepatol., vol. 3, no. 4, pp. 1-15, 2020.

[12] O. Lesi, M. Kehinde, and E. Anomneze, "Chronic liver disease in Lagos: A clinicopathological study," Niger Postgr. Med J, vol. 11, no. 2, pp. 91-96, 2004. 
[13] M. Ak et al., "Pattern of Liver Diseases," J Nepal Heal. Res Counc, vol. 7, no. 14, pp. 14-18, 2009.

[14] O. F. Bamidele, A. B. Olokoba, M. O. Bojuwoye, and R. O. Akintayo, "Prevalence of minimal hepatic encephalopathy among patients with chronic liver disease in Ilorin, Nigeria," Ghana Med J, vol. 53, no. 4, pp. 299-303, 2019.

[15] Ghana Statistical Service, "Population and Housing Census 2010," Accra, Ghana, 2012.

[16] M. Kooffreh-ada, H. Okpara, A. Oku, and P. A. Ihekwaba, "Risk factors of chronic liver disease amongst patients receiving care in a Gastroenterology practice in Calabar," IOSR J. Dent. Med. Sci., vol. 14, no. 12, pp. 6-13, 2015.

[17] Amadi CN and O. E. Orisakwe, "Herb-Induced Liver Injuries in Developing Nations: An Update," Toxics, vol. 6, no. 24, pp. $1-13,2018$.

[18] S. Abdelmenan et al., "Etiology of Chronic Liver Disease in Ethiopia: A Case Control Study with Special Reference to Viral Hepatitis and Alcoho," EC Gastroenterol Dig Syst, vol. 5 , no. 3, pp. 120-128, 2019.

[19] A. G. Ayele and S. Gebre-Selassie, "Prevalence and Risk Factors of Hepatitis B and Hepatitis C Virus Infections among Patients with Chronic Liver Diseases in Public Hospitals in Addis Ababa, Ethiopia," ISRN Trop Med, vol. 2013, pp. 1-7, 2013.

[20] J. Abesig, Y. Chen, H. Wang, F. M. Sompo, and I. X. Y. Wu, "Prevalence of viral hepatitis B in Ghana between 2015 and 2019 : A systematic review and meta-analysis," PLoS One, vol. 15 , no. 6 , pp. $1-16,2020$.

[21] R. Ofori-asenso and A. A. Agyeman, "Hepatitis B in Ghana: a systematic review \& meta-analysis of prevalence studies," BMC Infect. Dis., vol. 16, no. 130, pp. 1-15, 2016.

[22] M. J. Alter, "Epidemiology of hepatitis B in Europe and worldwide," J. Hepatol., vol. 39, no. 2003, pp. S64-S69, 2003.

[23] H. W. Zhang et al., "Risk factors for acute hepatitis B and its progression to chronic hepatitis in Shanghai, China," Hepatology, vol. 57, pp. 1713-1720, 2008.

[24] H. Ashraf et al., "Prevalence and risk factors of hepatitis B and $\mathrm{C}$ virus infections in an impoverished urban community in Dhaka, Bangladesh," BMC Infect. Dis., vol. 10, no. 208, pp. $1-8,2010$.

[25] United Nations, "Illiteracy Has Direct Impact on Human Health, Says Secretary-General in Message to Mark Literacy Day as $\mathrm{He}$ Calls for More Investment to Boost Reading Skills," Meetings Coverage and Press Releases, 2008. [Online]. Available: https://www.un.org. [Accessed: 10-Jul-2020].

[26] E. Castro-Sanchez, P. Chang, R. Vila-Candel, A. Escobedo, and A. Holmes, "Health Literacy and Infectious Diseases: Why Does It Matter?," Int J Infect Dis., vol. 43, pp. 103-110, 2016.

[27] WHO, "Why Health Litercay is Important," 2013. [Online]. Available: https://www.euro.who.int. [Accessed: 10-Jul-2020].

[28] B. J. Auerbach et al., "Traditional Herbal Medicine Use Associated with Liver Fibrosis in Rural Rakai, Uganda," PLoS One, vol. 7, no. 11, pp. 5-12, 2012.

[29] H. C. C. Study, K. Stene-johansen, S. G. Gundersen, and M. Y. Morgan, "Khat Chewing Increases the Risk for Developing Chronic Liver Disease : A," Hepatology, vol. 68, no. 1, pp.
$248-257,2018$.

[30] R. Teschke, C. Frenzel, X. Glass, J. Schulze, and A. Eickhoff, "Herbal hepatotoxicity: a critical review," Br. J. Clin. Pharmacol, vol. 75, no. 3, pp. 630-636, 2012.

[31] R. Teschke, A. Wolff, C. Frenzel, J. Schulze, and A. Eickhoff, "Herbal hepatotoxicity: A tabular compilation of reported cases," Liver Int., vol. 32, pp. 1543-1556, 2012.

[32] A. N. Mukerji, V. Patel, and A. Jain, "Improving Survival in Decompensated Cirrhosis," Int. J. Hepatol., vol. 2012, pp. 114, 2012.

[33] WHO, "What is hepatitis?," 2019. [Online]. Available: https://www.who.int. [Accessed: 10-Jul-2020].

[34] J. Perz, G. Armstrong, L. Farrington, Y. Hutin, and B. Bell, "The contributions of hepatitis B virus and hepatitis $\mathrm{C}$ virus infections to cirrhosis and primary liver cancer worldwide," $J$. Hepatol., vol. 45, pp. 529-538, 2006.

[35] WHO, Guidelines for the prevention, care and treatment of persons with chronic hepatitis $b$ infection, no. March. Geneva, Switzerland: WHO Press, 2015.

[36] WHO, Guidelines for the care and treatment of persons diagnosed with chronic hepatitis $c$ virus infection, no. July. Geneva, World Health Organization 2018, 2018.

[37] S. M. Alavian, M. H. Imanieh, and M. H. Imanieh, "Predictive Factors in the Incidence of Cirrhosis in Chronic Hepatitis B Virus Infections," Hepat Mon, vol. 16, no. 5, pp. 1-8, 2016.

[38] Y. Yu, M. Xu, Z. Wang, K. Liu, Z. Wang, and Z. Jiang, "MetaAnalysis of Risk Factors for Development of Liver Cirrhosis in Chronic Hepatitis B Patients," Glob J Infect Dis Clin Res, vol. 4, no. 2, pp. 1-9, 2018.

[39] S. B. Missiha, M. Ostrowski, and E. J. Heathcote, "Disease Progression in Chronic Hepatitis C: Modifiable and Nonmodifiable Factors," Gastroenterology, vol. 134, pp. 1699-1714, 2008.

[40] F. Kanwal et al., "HHS Public Access," Hepatology, vol. 60, no. 1, pp. 98-105, 2015.

[41] M. Bernardi, C. Maggioli, and G. Zaccherini, "Human albumin in the management of complications of liver cirrhosis," Crit. Care, vol. 16, no. 211, pp. 1-7, 2012.

[42] M. A. Merza, "Characteristics of Chronic Hepatitis B Virus Patients Related Liver Cirrhosis in a Tertiary Care Referral Hospital, Duhok, Iraqi Kurdistan," Gastroenterol Pancreatol Liver Disord, vol. 4, no. 5, pp. 1-5, 2017.

[43] M. Wrotkowska, P. Stalke, T. Smiatacz, and J. M. Zaucha, "Hematological Complications in Chronic Heaptitis C Virus Infection," Am. Soc. Hematol., vol. 124, no. 21, p. 2169, 2014.

[44] M. O. Amer and H. Elsiesy, "Ascites: Causes, Diagnosis, and Treatment," IntechOpen, pp. 117-137, 2017.

[45] O. A. Muhie, "Causes and Clinical Profiles of Ascites at University of Gondar Hospital, Northwest Ethiopia: Institution-Based Cross-Sectional Study," Can. J. Gastroenterol. Hepatol., vol. 2019, pp. 1-8, 2019.

[46] R. Shah, "Gastroenterology: Ascites," Medscape MedPulse News CME \& Education, 2017. [Online]. Available: https://www.medscape.com. [Accessed: 15-Apr-2019]. 
[47] M. Owusu et al., "Aetiology of viral hepatitis among jaundiced patients presenting to a tertiary hospital in Ghana," PLoS One, vol. 13, no. 9, pp. 1-14, 2018.
[48] M. Ochwoto et al., "Hepatitis B infection is highly prevalent among patients presenting with jaundice in Kenya," $B M C$ Infect. Dis., vol. 16, no. 101, pp. 1-14, 2016. 